\title{
Cutaneous lymphoid hyperplasia (pseudolymphoma)
}

\author{
Linghong Linda Zhou BHSc, Nisha Mistry MD
}

Cite as: CMAJ 2018 April 3;190:E398. doi: 10.1503/cmaj.170812

A 48-year-old otherwise healthy woman presented to the dermatology clinic with a six-week history of a red lesion on the right cheek. The lesion was generally asymptomatic, although the patient reported some occasional itch and tenderness. The referring primary care provider had made a presumptive diagnosis of acne cyst and prescribed treatment with doxycycline (100 mg administered orally and taken daily for 30 days), but there was no substantial change.

On examination, we found an infiltrated, erythematous nodule $(1.0 \mathrm{~cm} \times 1.5 \mathrm{~cm})$ on the patient's right medial cheek (Figure $1 \mathrm{~A}$ ). Our differential diagnosis included cutaneous lymphoma, pseudolymphoma, Jessner lymphocytic infiltration and plaque form of polymorphous light eruption.

The patient underwent a biopsy of the nodule that showed a diffuse polymorphous infiltrate of lymphocytes, histiocytes, plasma cells and a few eosinophils that were separated from normal appearing epidermis by a thin grenz zone (Appendix 1, available at www. cmaj.ca/lookup/suppl/doi:10.1503/cmaj.170812/-/DC1). Results from immunohistochemistry testing showed a mixed population of $B$ and $T$ cells. Based on these features, we diagnosed cutaneous lymphoid hyperplasia (pseudolymphoma).

Pseudolymphoma is a benign inflammatory response occasionally linked to an inciting antigen that simulates cutaneous lymphomas. The clinical presentation is a skin-coloured or red nodule on the face or chest, although multiple or generalized lesions can also be seen. ${ }^{1}$ Implicated antigens include medications (e.g., anticonvulsants, antidepressants, benzodiazepines, angiotensin-converting-enzyme inhibitors, $\beta$-blockers, calciumchannel blockers and lipid-lowering agents), tattoo dyes and bites from arthropods that are infected with bacterial spirochetes such as Borrelia burgdorferi (i.e., causative agent of Lyme disease), although most cases are idiopathic.

Because no offending agents were identified in our patient, Lyme serology testing was ordered for completeness, given the presence of Borrelia in Ontario; this association is more common in Europe than in North America. ${ }^{1,2}$ Results from this serology testing were also negative.

Treatment options for pseudolymphoma include observation, potent topical steroids, intralesional corticosteroids, cryosurgery, photochemotherapy, local radiation therapy and surgical excision. ${ }^{3}$ Our patient opted to proceed with topical steroids, which resulted in lesional resolution, with a remaining postinflammatory erythema (Figure $1 \mathrm{~B}$ ).

Although most pseudolymphomas regress spontaneously, development to lymphoma has been reported, necessitating close follow-up. ${ }^{4}$

\section{References}

1. Ploysangam T, Breneman DL, Mutasim DF. Cutaneous pseudolymphomas. J Am Acad Dermatol 1998;38:877-95.

2. Barker IK, Lindsay LR. Lyme borreliosis in Ontario: determining the risks. CMAJ 2000;162:1573-4.

3. Albrecht J, Fine LA, Piette W. Drug-associated lymphoma and pseudolymphoma: recognition and management. Dermatol Clin 2007;25:233-44.

4. Bergman R. Pseudolymphoma and cutaneous lymphoma: facts and controversies. Clin Dermatol 2010;28:568-74.

\section{Competing interests: None declared.}

This article has been peer reviewed.

The authors have obtained patient consent.

Affiliations: Faculty of Medicine (Zhou), University of Ottawa, Ottawa, Ont.; Division of Dermatology (Mistry), Department of Medicine, University of Toronto, Toronto, Ont.

Acknowledgement: The authors thank Dr. Dalal Assaad, Division of Dermatology, University of Toronto, for providing the pathology images.

Correspondence to: Linghong Linda Zhou, lzhou026@uottawa.ca 